\title{
Catchments catch all in South African coastal lowlands: topography and palaeoclimate restricted gene flow in Nymania capensis (Meliaceae) - a multilocus phylogeographic and distribution modelling approach
}

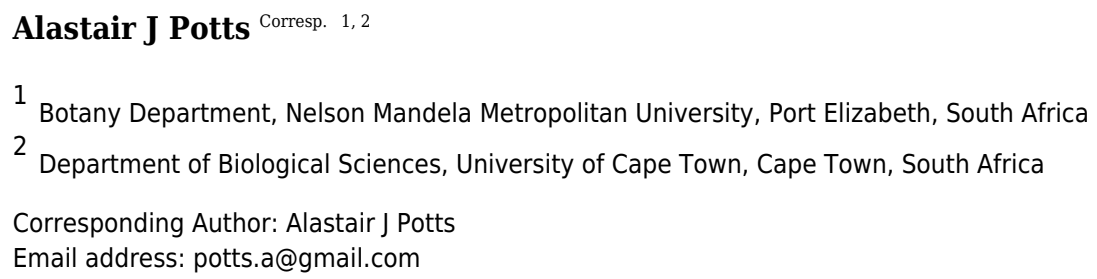

Background. This study investigates orbitally-forced range dynamics at a regional scale by exploring the evolutionary history of Nymania capensis (Meliaceae) across the deeply incised landscapes of the subescarpment coastal lowlands of South Africa; a region home to three biodiversity hotspots (Succulent Karoo, Fynbos, and Maputaland-Pondoland-Albany hotspots).

Methods. A range of methods are used including: multilocus phylogeography (chloroplast and high- and low-copy nuclear DNA), molecular dating and species distribution modelling (SDM).

Results. The results support an 'evolutionarily distinct catchment' hypothesis where: (1 different catchments contain genetically distinct lineages, 2) limited genetic structuring was detected within basins whilst high structuring was detected between basins, and 3) within primary catchment populations display a high degree of genealogical lineage sorting. In addition, the results support a glacial refugia hypothesis as: a) the timing of chloroplast lineage diversification is restricted to the Pleistocene in a landscape that has been relatively unchanged since the late Pliocene, and b) the projected LGM distribution of suitable climate for $\mathrm{N}$. capensis suggest fragmentation into refugia that correspond to the current phylogeographic populations.

Discussion. This study highlights the interaction of topography and subtle Pleistocene climate variations as drivers limiting both seed and pollen flow along these lowlands. This lends support to the region's large-scale conservation planning efforts, which used catchments as foundational units for conservation as these are likely to be evolutionary significant units. 
1 TITLE: Port Elizabeth, South Africa, 6000.

\section{Alastair J. Potts} Town, South Africa, 7701.

Catchments catch all in South African coastal lowlands: topography and palaeoclimate restricted gene flow in Nymania capensis (Meliaceae) - a multilocus phylogeographic and distribution modelling approach

SHORT HEADER: Catchments catch all in a lowland plant species

Department Biological Sciences, University of Cape Town, Private Bag X3, Rondebosch, Cape

Botany Department, Nelson Mandela Metropolitan University, Summerstrand Campus (South),

\section{Abstract}

Background. This study investigates orbitally-forced range dynamics at a regional scale by exploring the evolutionary history of Nymania capensis (Meliaceae) across the deeply incised landscapes of the subescarpment coastal lowlands of South Africa; a region home to three biodiversity hotspots (Succulent Karoo, Fynbos, and Maputaland-Pondoland-Albany hotspots). Methods. A range of methods are used including: multilocus phylogeography (chloroplast and high- and low-copy nuclear DNA), molecular dating and species distribution modelling (SDM). 
21 Results. The results support an 'evolutionarily distinct catchment' hypothesis where: 1)

22 different catchments contain genetically distinct lineages, 2) limited genetic structuring was

23 detected within basins whilst high structuring was detected between basins, and 3) within

24 primary catchment populations display a high degree of genealogical lineage sorting. In

25 addition, the results support a glacial refugia hypothesis as: a) the timing of chloroplast lineage

26 diversification is restricted to the Pleistocene in a landscape that has been relatively unchanged

27 since the late Pliocene, and b) the projected LGM distribution of suitable climate for $N$. capensis

28 suggest fragmentation into refugia that correspond to the current phylogeographic

29 populations.

30 Discussion. This study highlights the interaction of topography and subtle Pleistocene climate

31 variations as drivers limiting both seed and pollen flow along these lowlands. This lends support

32 to the region's large-scale conservation planning efforts, which used catchments as

33 foundational units for conservation as these are likely to be evolutionary significant units. 


\section{Introduction}

37 Climate changes driven by variations in the Earth's orbit, i.e. Milankovitch oscillations, have

38 influenced the distribution of species and clades across the globe. Jansson \& Dynesius (2002)

39 termed this "orbitally-forced range dynamics" (ORD) and highlight that this process drives

40 extinction, splitting, and merging of gene pools and clades. The magnitude of ORD varies

41 geographically, primarily latitudinally with greater ORD in the poles and a decline towards the

42 equator (Dynesius \& Jansson 2000). Gene pools should persist without going extinct or merging

43 in areas with low ORD, leading to long term splitting and diverging of clades; Jansson \&

44 Dynesius (2002) call this $\beta$-clade formation where evolutionary change persists for more than

$45100 \mathrm{kyr}$. Here I explore the role of ORD on a regional scale, specifically in terms of the

46 interaction between glacial-inter-glacial climate changes and topography (i.e. watershed

47 configuration) on a tree species, Nymania capensis (Meliaceae), across a section of the

48 subescarpment coastal plains in South Africa.

Nymania capensis is associated with the subtropical thicket vegetation in South Africa, locally

51 termed the Albany Subtropical Thicket. This region forms the western part of the Maputaland-

52 Pondoland-Albany biodiversity hotspot (Steenkamp et al. 2004). Thicket vegetation is

53 characterised as dense, woody, semi-succulent and thorny, with an average height of 2-3 m,

54 and is relatively impenetrable in a pristine condition (Vlok et al. 2003). It is largely restricted to

55 the subescarpment coastal plains along the south coast of South Africa where it spans a

56 number of deeply incised primary catchments. Although thicket has a continuous or near- 
57 continuous distribution across catchments, each catchment has been identified as a discrete

58 biogeographic unit (Vlok et al. 2003) suggesting that the watersheds have been dispersal

59 barriers to thicket plant species. This pattern, termed here as the "evolutionarily discrete

60 catchment" (EDC) hypothesis, has formed the foundation of large-scale conservation planning

61 that aims to ensure the persistence of evolutionary processes for thicket biota (Rouget et al.

62 2006). This hypothesis can be seen as a specific case of low ORD where the topographic

63 heterogeneity of the deeply incised subescarpment lowlands coupled with climate stability has

64 enabled $\beta$-clade formation, i.e. clades that have survived and remained genetically separate for

65 longer than 100 kyr. Under the EDC hypothesis, a number of predictions can be generated if

66 catchments and their associated watersheds are important landscape features responsible for

67 structuring genetic diversity (sensu Potts et al. 2013c; Price et al. 2010):

(1) Different catchments should contain genetically distinct lineages,

(2) There should be limited genetic structuring within catchments and a high degree of genetic structuring among basins, and

(3) If watersheds have been long term barriers to gene flow, then isolated catchment populations should contain evidence of genealogical sorting.

74 Southern Africa did not experience glaciation during the Pleistocene climate cycles (Partridge 1997). Nonetheless, these watershed barriers are suggested to have been greatly strengthened during the Pleistocene as thicket is predicted to have severely contracted into, and fragmented across, catchments (Cowling et al. 2005; Potts et al. 2013c): a glacial multiple refugia (GMR) 
78 hypothesis (a low ORD scenario). If thicket species were adversely affected by glacial climates

79 through the Pleistocene, in interaction with the topography, then the following is predicted:

80 (4) The timing of population subdivision between the catchments should coincide with the

(5) The species' distribution should experience contraction and fragmentation that is

87 There is growing support that these EDC-GMR hypotheses apply to thicket vegetation (Duker et al. 2015a; Potts et al. 2013c). Plastid lineages from thicket taxa Nymania capensis and Pappea capensis have previously been shown to be isolated to primary catchments (Potts et al. 2013b). However, being strongly geographically constrained, plastid markers may give a biased representation of a species' genetic coherence (Premoli et al. 2012) or evolutionary history, as the smaller effective population size of uniparentally-inherited markers render them more susceptible to stochastic processes (Edwards \& Beerli 2000). Therefore, this study provides an

94 in-depth phylogeographic examination of Nymania capensis by combining the results from Potts et al. (2013b) with data from high and low copy nuclear regions. These data are used to test the EDC hypothesis by determining whether populations within populations are

97 evolutionarily significant units (sensu Moritz 1994). In addition, molecular dating of the 98 chloroplast dataset and hindcasting of species distribution models are used to explore the GMR 
99 hypothesis. The results are contrasted with the predictions generated from these two

100 hypotheses.

101

102 Materials and Methods

103 Study system

104 Thicket is restricted to the year-round rainfall zone along the coastal lowlands of South Africa. A

105 winter rainfall zone is found to the west and a summer rainfall zone to the east. The

106 subescarpment coastal lowlands form a series of short but deeply incised catchments separated

107 from an unusually elevated interior plateau by the Great Escarpment. The coastal lowland

108 landscape has been topographically stable and relatively unchanged since the end of the

109 Pliocene ( 2.6 Ma; Cowling et al. 2009) and possibly even longer (Scharf et al. 2013).

110

111 The distribution of $N$. capensis in the Albany Subtropical Thicket spans three primary

112 catchments along the coastal lowlands, specifically the Gouritz, Gamtoos and Sundays (named

113 after the major rivers within each catchment). However, the Gouritz catchment has additional

114 topographic complexity as two parallel mountain ranges associated with the Cape Fold Belt run

115 across it, creating an intermontane basin known as the Little Karoo. An inselberg, the Rooiberg

116 Mountain, splits this intermontane basin along a west-east orientation (see Fig. 1a). This

117 inselberg has been found to be a barrier to gene flow in another terrestrial plant species

118 endemic to the Little Karoo (Potts et al. 2013a), so the secondary catchments west and east of 
119 the Rooiberg (Groot and Olifants, respectively) were sampled as extensively as the primary

120 catchments.

121

\section{Study species}

123 Nymania is a monotypic, woody genus of Meliaceae restricted to southern Africa (see Appendix

124 S1 for images of the growth habit, flowers and inflated seed capsules). Solitary flowers are

125 borne on leaf axils and are generally pollinated by insects (J.H.J. Vlok and A.J. Potts, pers. obs.).

126 The fruit is an inflated and deeply lobed capsule with papery thin membranes, and contains

127 numerous small seeds. The seeds are carried away from the parent plant within the light

128 inflated capsules that are blown along the ground by wind or carried along by water. The

129 inflated capsule is peculiar in this species as it is not described anywhere else in the Meliaceae

130 (Pennington \& Styles 1975).

131

132 This species occurs across a wide range of environmental conditions and is split into two

133 disjunct distributions, one in the southern semi-arid region ( $300-600 \mathrm{~mm}$ annual rainfall) of

134 the Albany Subtropical Thicket and the other in the northern arid region ( $100-300 \mathrm{~mm}$ annual

135 rainfall) of South Africa, which is a mosaic of Subtropical Thicket and Nama-Karoo vegetation.

136 Preliminary morphological (A.E. van Wyk, pers. com.) and genetic data (two samples used in

137 this study) suggest that the northern distribution that extends from the Nama-Karoo into

138 Namibia and the southern distribution, which is restricted to the Albany Thicket, are different

139 species. The northern and southern distributions of $N$. capensis are separated by a distance of

140 over $400 \mathrm{~km}$ spanning the Great Escarpment mountain range and the interior elevated plateau 
141 of South Africa. This species was selected because (i) it is a common component of the Albany

142 Thicket, (ii) for its ease of location and identification in the landscape, and (iii) human activities,

143 such as livestock farming, do not appear to have affected its local distribution in the landscape

144 (personal observations).

146 Samples and DNA data

147 Sampling consisted of one individual from each of 78 localities across the thicket. Sampling

148 permits were obtained from the Eastern Cape Parks and Tourism Agency and CapeNature

149 (0028-AAA008-00015). The sampling strategy was focussed on maximising the number of sites

150 sampled in order to explore the broad scale regional patterns rather than intra-population

151 differences. This scattered sampling strategy is also not affected by local and rapid coalescence

152 events (Städler et al. 2009) and thus gives an unbiased view of population structuring and

153 demographic history. Thus, each catchment was represented by 14 to 26 individuals, with

154 nearly all individuals selected from localities that were over $10 \mathrm{~km}$ apart. Two samples of $N$.

155 capensis from the northern distribution stored in the Bolus Herbarium were used to generate

156 outgroup accessions (BOL48535 and BOL60966).

158 Three DNA sequence markers were analysed: chloroplast DNA and nuclear DNA from high and

159 low copy regions. Chloroplast DNA accessions of the trnQ-5'-rps16 and atpl-atpH regions (from

160 Potts et al. 2013b) are treated as linked regions as they are inherited in tandem. Nuclear DNA

161 sequence data were obtained from two loci, the high-copy ITS region of the 35S rDNA cistron

162 (the 5.8S rDNA and the flanking internal transcribed spacers, ITS-1 and ITS-2) (from Potts et al. 
163 2014, complemented with additional accessions) and the low-copy chloroplast-expressed

164 glutamine synthetase gene (ncpGS; new data). Extraction and PCR protocols are reported in 165 Appendix S2.

166

167 Details of sequence alignment and, in the case of nuclear DNA, the detection of intra-individual

168 site polymorphisms (2ISPs) are given in Potts et al. (2014). In brief, multiple variants of a nuclear

169 region may be present within an individual which give rise to 2ISPs. These can be observed as

170 double (and even triple) peaks in trace files and were coded using the extended IUPAC

171 nucleotide codes (e.g. Y, R); these codes are commonly referred to as 'ambiguity' codes, but it is

172 important to note that 2ISPs are not the result of uncertain coding due to scrappy trace files but

173 rather the clear presence of two or more bases. Numerous 2ISPs were observed in direct-PCR

174 sequences from both nuclear regions, thus indicating the presence of more than one DNA

175 variant present in the genome. This has been observed in many other plant species (Bailey et al.

176 2003), and is unsurprising given the complexity of the nuclear regions, especially ITS.

178 How accurate is direct-PCR sequencing for detecting 2ISPs? This question has not been

179 investigated in-depth in this study or elsewhere. However, using a small subset of $N$. capensis

180 samples, I found a high degree of congruence between direct-PCR and cloned samples with a

181 low false detection rate; two other studies show similar findings (see Appendix S2 for further

182 details). Both ITS and ncpGS cloned samples demonstrated that these regions contained

183 multiple copies of each region per sample (see supplementary data files). This rules out

184 statistically inferring phased haplotypes from polymorphic sequences as these methods assume 
185 a maximum of two copies per individual (e.g. PHASE, Stephens et al. 2001) and cloning all

186 samples was prohibitively expensive.

187 All datasets aligned readily and reliable gaps corresponding to insertion or deletion events were

188 included as informative characters; indels that were not associated with homopolymer repeats

189 were coded as binary characters and used in all analyses (multiple base indels were treated as

190 single characters). Where 2ISPs comprised an indel and a base or bases (observed in the ITS

191 dataset), then these were given a unique code for inclusion into subsequent analyses as no

192 IUPAC nucleotide code exists for this combination.

193

194 Phylogenetic and phylogeographic analyses

195 The phylogenetic relationships between chloroplast, ncpGS haplotypes and all ITS ribotypes

196 were inferred using Statistical Parsimony (SP) and NeighbourNet (NN) networks in TCS version

1971.21 (Clement et al. 2000) and SplitsTree version 4.8 (Huson \& Bryant 2006), respectively. In

198 order to accommodate the 2ISPs present in the ncpGS and ITS datasets, polymorphism $p$ -

199 distances (Potts et al. 2014) were used to calculate both SP and NN networks; this measure

200 specifically incorporates 2ISPs when calculating genetic distances (these sites are usually

201 removed or averaged) and was obtained using the PHANGORN library (Schliep 2011) in R3.0.1 (R

202 Core Team 2015). Consensus networks generated from 1000 bootstraps using Neighbour

203 Joining, Maximum Parsimony or Maximum Likelihood were used to assess edge support in the

204 SP and NN networks; details of software used and settings are given in Potts et al. (2014) but, in

205 brief, PAUP* version 4b10 (Swofford 2002) and RAxML version 7.2.6 (Stamatakis 2006;

206 Stamatakis et al. 2008) were used under the 2ISP-informative approach. The standard 
207 treatment of 2ISPs by phylogenetic software is that the actual nucleotide is uncertain (or

208 'ambiguous') and this usually leads to an erosion of phylogenetic support. The 2ISP-informative

209 approach avoids this by forcing the phylogenetic algorithms to treat 2ISPs as additional

210 information (Potts et al. 2014).

211

212 Bayesian software such as MrBayes (Ronquist \& Huelsenbeck 2003) or BEAST (Drummond \&

213 Rambaut 2007) cannot incorporate 2ISPs as informative characters (Potts et al. 2014) and

214 return unresolved topologies for the ITS and ncpGS alignments (results not shown).

216 The level of genealogical divergence was assessed using the genealogical sorting index (gsi,

217 Cummings et al. 2008). The gsi statistic is a standardised measure of the extent to which

218 predefined groups in a gene tree exhibit exclusive ancestry (fall within a distinct clade); the gsi

219 statistic ranges from 0 (a complete lack of genealogical divergence with respect to other

220 groups) to 1 (monophyly: all elements of a predefined group fall within the same, exclusive

221 subtree). Further details are provided in Appendix S2.

222

223 Pairwise genetic and geographic distances among sampling locations within and between

224 catchments were used to test patterns of isolation by distance using a Mantel test (Mantel

225 1967). Genetic distance for cpDNA was calculated using uncorrected $p$-distances, whereas ITS

226 and ncpGS genetic distances were calculated using polymorphism $p$-distances (Potts et al.,

227 2014). Standard genetic and geographic distances were calculated using the APE library version 
228 3.0-9 in R (Paradis et al. 2004). The probability and significance of the correlation coefficient

229 (Spearman's R) was estimated after 10,000 permutations.

230

231 Molecular dating

232 Given the dominance of 2ISPs in the nuclear datasets, only the cpDNA could be used for

233 molecular dating; a molecular clock approach using such individual consensus sequences is not

234 yet feasible and the alternative 2ISP resampling procedure suggested by Lischer et al. (2013)

235 generates exceptionally wide and uninformative date ranges due to the high proportion of

236 2ISPs in the ITS dataset (results not shown). Assigning a timescale to phylogenies typically

237 involves ingroup fossils as age constraints or applying a rate of molecular evolution. No fossil or

238 pollen data specific to $N$. capensis are available, so the hypothesis of Pleistocene lineage

239 evolution was tested using a highly conservative approach by using the 'extremes' of

240 substitution rates found in the literature for non-coding chloroplast DNA, specifically $1.0 \times 10^{-9}$

241 (Richardson et al. 2001) and $31 \times 10^{-9}$ substitutions per site per year (Fu \& Allaby 2010). The

242 dating of lineage divergence was carried out using BEAST version 1.4.8 (Drummond \& Rambaut

243 2007), which estimates the tree topology and the date (height) of nodes simultaneously using a

244 Bayesian approach. The BEAST analysis was performed using all cPDNA samples as this sampling

245 is important for coalescent estimation of lineage divergence. Further details are provided in

246 Appendix S2.

247 


\section{Distribution modelling}

249 The details of the species distribution modelling, including hindcasting the models to Last

250 Glacial Maximum climate conditions are given in Potts et al. (2013b). In brief, an ensemble

251 species distribution modelling approach (sensu Araújo \& New 2007) was used where the

252 uncertainty generated by locality selection, parameter selection of current climate and

253 distribution modelling algorithm could be assessed; this resulted in an ensemble of 216 models.

254 These models were then projected onto the statistically downscaled CCSM global climate

255 model that is available from http://www.worldclim.org. All projections were converted to

256 binary presence-absence maps using the equal sensitivity plus specificity threshold criterion.

257 These models were further interrogated, using the SDMTools library version 1.1-13 (VanDerWal

258 et al. 2011) in R3.0.1, by calculating the area and patch cohesion index within each catchment

259 for each model combination within the ensemble for both current and past climate.

260

261

262 Results

263 Genetic data characteristics

264 The final chloroplast dataset is comprised of 1948 bp (trnQ-5'-rps16: 791 bp; atpl-atpH: 1157

265 bp). The ITS and ncpGS datasets were comprised of $666 \mathrm{bp}$ and $1089 \mathrm{bp}$, respectively. Sequence

266 characteristics for each dataset are summarised in Table 1. Haplotype/ribotype and nucleotide

267 diversity were high in the ITS dataset, moderate in the chloroplast dataset, and low in the 
268 ncpGS dataset. Summaries of variable sites across the chloroplast and ncpGS haplotypes, as

269 well as a subset of ITS samples, are shown in Appendix S3, respectively.

270

271 Two individuals situated in the Gamtoos had chloroplast haplotypes and ITS genotypes

272 associated with the Sundays catchment lineage, however these were very close ( $\leq 5 \mathrm{~km})$ to the

273 watershed suggesting incorrect watershed delineation or recent migration rather than

274 incomplete lineage sorting. Thus, these samples were grouped with the Sundays basin samples

275 for all analyses.

276 Phylogeographic analyses

277 Under the evolutionarily discrete catchment (EDC) hypothesis, different catchments should

278 contain genetically distinct lineages (Prediction 1). The catchment association was strong with

279 chloroplast haplotypes, with all but one haplotype restricted to one of the primary or secondary

280 catchments (Fig. 1b). A strong association was also evident between primary catchments and

281 ITS clusters (Fig. 1d) with two exceptions (indicated with arrows, discussed further below). Only

282 rare ncpGS haplotypes were restricted to catchments, whereas two widespread haplotypes

283 were shared either among both subregions of the Gouritz or among both Gamtoos and Sundays

284 catchments (Fig. 1c). Two samples contained anomalous ncpGS haplotypes; these haplotypes

285 are found in an intermediate position between the western and eastern haplotypes. They may

286 represent inherited ancestral copy diversity or recent gene flow (subsequent intragenomic

287 recombination) between samples from the western and eastern basins. However, given the

288 slow rate of mutation in this region, evident by the low genetic diversity, and that one of these

289 intermediate haplotypes is also shared with an outgroup sample from the northern distribution 
290 (BOL48535; Supplementary files), it is likely that these haplotypes represent ancestral and

291 unsorted ncpGS copies.

292

293 Samples AJP0537 and AJP0810 (indicated with arrows in Figure 1b-d) lie within the Gamtoos

294 catchment, but are close to sampled localities with a Sundays catchment genetic signature

295 found on the watershed boundary between the catchments. These samples have Gamtoos

296 chloroplast haplotypes, and for ncpGS, a rare Gamtoos haplotype, as well as a common and

297 widespread haplotype. However, the first sample has an ITS signal that nests it within the

298 Sundays ITS cluster 3, while the second displays a recombinant signal that lies between the

299 Gamtoos cluster 2 and cluster 3 (Fig. 1d). The contrasting basin associations between these two

300 samples suggest that they represent a contact zone between the Sundays and Gamtoos

301 lineages, possibly caused by pollen flow between plants in this zone. As these samples are

302 anomalous to the overall patterns of association, and are geographically restricted, they were

303 removed for all subsequent analyses.

304

305 Isolation by distance using the Mantel Test (MT) was used to determine if there was genetic

306 structuring within and between catchments (Prediction 2). In general, non-significant $\mathrm{MT}_{R}$

307 values were observed within the primary or secondary catchments (Table 1 ) across the

308 different DNA regions; however, there were a few instances where significant but low $\mathrm{MT}_{\mathrm{R}}$ (ITS

309 in Sundays; ncpGS in Olifants) and significant but high $\mathrm{MT}_{\mathrm{R}}$ values (in comparison to the overall

310 value; ITS in Gamtoos) were observed. There were significant and high $\mathrm{MT}_{\mathrm{R}}$ values between the

311 Olifants and Gamtoos basins across all DNA regions. Significant $\mathrm{MT}_{\mathrm{R}}$ values between the Groot 
312 and Olifants and the Gamtoos and Sundays were only observed in the cPDNA and ITS; however,

313 the $\mathrm{MT}_{\mathrm{R}}$ values were low for the former pair of basins and high for the latter pair.

314

315 If watersheds have been evolutionarily long term barriers to gene flow then topographic-driven

316 isolation should be evident, culminating in sorting, and ultimately monophyly, of lineages

317 within catchments (Prediction 3). Although monophyletic lineages were detected with

318 moderate to high support (60\%-98\%) in the chloroplast bootstrap phylogenies, only samples

319 from the Gamtoos catchment displayed catchment-based monophyly (Fig. 1b). In contrast, the

320 ITS produces high support for Gouritz, Gamtoos and Sundays lineages (Fig. 1d). No

321 monophyletic lineages were found to be restricted to any catchments in the ncpGS data, but

322 this is due to two widespread haplotypes and low diversification rates. Despite lack of

323 supported monophyly in the cpDNA and ncpGS analyses, the gsi results do suggest a high level

324 of lineage sorting $(>0.600)$ in the western Gouritz basin for both datasets, and in the Gamtoos

325 and Sundays for cpDNA (Table 1).

326

327 A BEAST analysis was used to date the diversification of chloroplast lineages in order to

328 determine whether the Pleistocene climate cycles have also played a role in population

329 isolation in catchments (Prediction 4). The timing of all of the thicket lineages fall firmly within

330 the Pleistocene whether a 'fast' or 'slow' rate of chloroplast mutation is used (Fig. 2). Species

331 distribution modelling suggests that $N$. capensis experienced major range contractions and

332 fragmentation during the Last Glacial Maximum (Fig. 3, Prediction 5), finding refugia within

333 each of the catchments and current distribution. 


\section{Discussion}

336

337 In a broad sense, this study makes use of both genetic and geospatial data in order to explore

338 -clade formation driven by "orbitally-forced range dynamics" (ORD; Jansson \& Dynesius 2002)

339 in a region that remained free of glaciation during the Pleistocene. More specifically, it tests the

340 predictions of two ORD-related hypotheses regarding the effects of topography and Pleistocene

341 climate fluctuations on the genetic diversity of Nymania capensis within the Albany Subtropical

342 Thicket: the evolutionarily distinct catchment (EDC) hypothesis and the glacial multiple refugia

343 (GMR) hypothesis. The former hypothesis was generated from a phytosociological study of

344 thicket (Vlok et al. 2003) where catchments were identified as discrete biogeographic units,

345 whereas the latter was generated from biome-level distribution modelling (Potts et al. 2013c)

346 and observations of physiological sensitivity to declining temperatures of thicket species

347 (Cowling et al. 2005; Duker et al. 2015a). From these hypotheses, five predictions were

348 generated and tested using Nymania capensis. The results suggest that catchments have been

349 in situ refugia (Gavin et al. 2014; Tzedakis 1993) for N. capensis during glacial-interglacial cycles

350 with glacial refugia largely located within the interglacial distribution.

352 Evolutionarily discrete catchments: watersheds and catchments as drivers of diversification 
354 Investigating the role that catchment topography plays in reducing gene flow and driving

355 population divergence has largely been restricted to either obligate freshwater animal species

356 (e.g. redfins, Swartz et al. 2009) or freshwater animal species capable of terrestrial movement

357 (e.g. freshwater crayfish, crabs, salamanders, and spotted frogs; Cook et al. 2008; Funk et al.

358 2005; Giordano et al. 2007; Ponniah \& Hughes 2006). Only recently have catchments and

359 watersheds been explored as drivers of diversification in terrestrial species that do not rely on

360 the riparian system, and these have mostly focussed on invertebrates (e.g. springtails and

361 cicadas; Garrick et al. 2007; Garrick et al. 2004; Price et al. 2010). The EDC hypothesis for the

362 catchments in this study area is supported by two other studies, one on fish (Swartz et al. 2009)

363 and the other on cicadas (Price et al. 2010).

364

365 The phylogeographic patterns of $N$. capensis are largely consistent with the three predictions

366 deduced from the EDC hypothesis. Firstly, the predominant pattern is one of genetically distinct

367 lineages restricted to single catchments (Fig. 1), although a few lineages span neighbouring

368 catchments. The number of genetically distinct lineages varies between the different markers;

369 this is expected given their different rates of mutation and effective population sizes. Secondly,

370 there is limited genetic structuring within catchments as most analyses did not detect a within-

371 basin signal of isolation by distance. In contrast, a large and significant isolation by distance

372 effect is evident across all catchments (Table 1). This suggests that gene flow is hindered

373 between basins, while this is not the case within basins. Lastly, although catchments do not

374 contain genetically homogenised and fully isolated lineages, there is strong evidence of

375 genealogical sorting within each catchment (Table 1). 
377 The strong phylogeographic break between the western Gouritz and the eastern Gamtoos and

378 Sundays catchments detected in this study corresponds to previously documented breaks

379 observed within Meleuphorbia (Euphorbiaceae, Ritz et al. 2003) and Platypleura plumosa

380 (Hemiptera: Cicadidae, Price et al. 2010). The Rooiberg inselberg that separates the Groot and

381 Olifants basin has been observed as a phylogeographic break in Platypleura karooensis

382 (Hemiptera: Cicadidae, Price et al. 2010) and Berkheya cuneata (Asteraceae, Potts et al. 2013a).

383 However, although only one chloroplast haplotype is shared between these subcatchments,

384 which is suggestive of restricted seed flow, there is very weak support for isolation by distance

385 or genealogical sorting across all DNA regions.

386

387 Thus, the results of this study provide additional support for the EDC hypothesis as the marked

388 genetic structuring revealed in $N$. capensis is consistent with patterns predicted on the basis of

389 primary catchment divisions. However, although the landscape has been stable since the Late

390 Pliocene (Cowling et al. 2009), dramatic cycling between glacial and inter-glacial climates has

391 occurred during the Pleistocene. These shifts may have also affected the distribution,

392 fragmentation and divergence of thicket species such as Nymania capensis (Cowling et al. 2005;

393 Dynesius \& Jansson 2000).

Glacial refugia: Pleistocene climatic cycles as drivers of diversification

396 If the Pleistocene climate cycling between glacial and interglacial periods was responsible for

397 isolating populations in this landscape - which has been stable since the late Pliocene ( 2.6 Ma; 
398 Cowling et al. 2009) - then it would be expected that lineage diversification would coincide or

399 occur after the onset of these cycles. There are many potential problems with the molecular

400 clock approach (Graur \& Martin 2004; Ho 2007), and selecting an accurate rate of substitution

401 for target taxa is of primary concern when fossil calibration is not possible. Using a wide range

402 of published substitution rates for non-coding chloroplast DNA should circumvent the lack of an

403 accurate rate for Nymania capensis. Using both slow and fast substitution rates, the divergence

404 of all thicket lineages falls well within the Pleistocene (Fig. 2), suggesting that this species has

405 experienced fragmentation and isolated diversification during this period. Under the fast

406 substitution rate, many of the lineages diverge after the Last Glacial Maximum. This is,

407 however, an unlikely scenario given that this is an exceptionally fast rate that has been derived

408 from a genus of annual herbs (Linum) and the fast turnover in generations is likely to have

409 greatly increased the substitution rate (Kay et al. 2006). Nymania capensis is a perennial plant

410 that requires more than five years of ideal environmental conditions before flowers and seeds

411 are produced (Jan Vlok, pers. comm.). It is thus highly unlikely that its substitution rate would

412 coincide with that of an annual herb, leading to the conclusion that lineage diversification fell

413 within the Pleistocene. The slower substitution rate also falls within the generally accepted

414 range of 1.0 to $3.0 \times 10^{-9}$ (Wolfe et al. 1987 ).

415

416 Climatic changes during the Pleistocene glacial cycles have induced distributional shifts in

417 species, often resulting in fragmentation and divergence of populations (Hewitt 2004; Fig. 3;

418 Jansson \& Dynesius 2002). Identifying refugial areas during glacial periods through the

419 Pleistocene has been a strong focus within many phylogeographic studies (Avise 2000), with the 
420 majority of studies focussed on the previously glaciated northern hemisphere regions (Abbott

421 et al. 2000; Soltis et al. 1997; Taberlet et al. 1998). Southern Africa did not experience glaciation

422 during the Pleistocene climate cycles (Partridge 1997) and determining refugia for plant species

423 in areas that did not experience glaciation is a challenging process (e.g. Byrne 2007).

424 Nevertheless, in the Cape Floristic Region, which neighbours the thicket, climatic fluctuations

425 during the Pleistocene have been suggested to be the main driver of fragmentation and shifts in

426 faunal species distributions, culminating in allopatric diversification (e.g. rock agama, dwarf

427 chameleons, and cicadas; Price et al. 2007; Swart et al. 2009; Tolley et al. 2006). The lower

428 temperatures, both globally (Zachos et al. 2001) and regionally (Holmgren et al. 2003; Talma \&

429 Vogel 1992), coupled with the frost sensitivity observed in many of the thicket's component

430 species (Duker et al. 2015a; Duker et al. 2015b) is suggested to have driven thicket vegetation

431 into fragmented refugia (Cowling et al. 2005), as reflected by Nymania capensis.

432

433 Climatic changes will drive shifts in geographic distributions of species (Jansson \& Dynesius

434 2002) if they cannot adapt to new ecological conditions, at least over moderate periods of time.

435 Evidence suggests that niche conservatism may be general and pervasive across most species

436 over moderate periods of time, despite profound changes in climate and environmental

437 conditions (Martínez-Meyer \& Peterson 2006; Martínez-Meyer et al. 2004; Peterson et al.

438 1999). Here I assume that the niche of $N$. capensis has been largely conserved from the LGM to

439 the present.

440 The species distribution modelling results of $N$. capensis suggest this species' range contracted

441 and fragmented into and within the primary catchments (Fig. 3). This is consistent with the 
442 phylogeographic evidence that suggests isolation into at least three refugia which correspond

443 to the delimitation of primary basins (Fig. 1). Thus, the retraction into catchments during glacial

444 periods through the Pleistocene would have strengthened the effects of watershed barriers to

445 gene flow. This retraction is consistent with the limited palaeodata (reviewed in Cowling et al.

446 2005) and community distribution modelling of thicket subtypes (Potts et al. 2013c) that also

447 suggests that thicket suffered significant range constrictions during the most recent Pleistocene

448 glacial period. Also, the absence of vertebrates endemic to the thicket, which would be

449 expected given the present-day area of the biome, is suggestive of historical reduction and

450 fragmentation of the biome's distribution (Hoare et al. 2006).

451

452 The EDC hypothesis has been used as the cornerstone for conservation planning in the Albany

453 Subtropical Thicket in order to conserve both the biodiversity patterns and evolutionary

454 processes of this vegetation (Rouget et al. 2006). Specifically, a number of conservation

455 corridors have been identified to create a mega-conservancy network; these corridors are

456 predominantly focussed on conserving major environmental gradients primarily within

457 catchments. These results demonstrate that the patterns observed in the chloroplast

458 phylogeography (Potts et al. 2013b) are mirrored in the nuclear genome, suggesting that the

459 catchments house evolutionarily significant units (sensu Crandall et al. 2000; Moritz 1994).

460

461 In conclusion, the results from these phylogeographic analyses and ensemble niche modelling

462 suggest that the genetic structuring of $N$. capensis has been determined by landscape topology

463 coupled with the effects of fluctuating Pleistocene climates. Populations have been restricted 
464 to three primary catchments with no extensive present-day or historical gene flow during the

465 previous glacial period. This is largely consistent with the predictions derived from a scenario

466 where landscape topography and climatic fluctuations were responsible for structuring

467 populations across the southern African lowlands. From their glacial refugia they (re-)colonised

468 their modern range, a process that is apparently accompanied by secondary contact and

469 introgression ('anomalous' Gamtoos samples). The findings validate and further highlight the

470 importance of including catchments in conservation planning as discrete and evolutionarily

471 significant units important for maintaining genetic resources.

472

473 Acknowledgements

474 The author gratefully acknowledges Richard M. Cowling, Terry A. Hedderson, Guido W. Grimm,

475 and three anonymous reviewers for comments that greatly improved this manuscript. In

476 addition, Jan Vlok is thanked for sharing his knowledge regarding his extensive natural history

477 observation of this species and the thicket vegetation.

478

\section{References}

480

481

482

483

484

485

486

487

488
Abbott RJ, Smith LC, Milne RI, Crawford RMM, Wolff K, and Balfour J. 2000. Molecular analysis of plant migration and refugia in the Arctic. Science 289:1343-1346.

Araújo MB, and New M. 2007. Ensemble forecasting of species distributions. Trends in Ecology \& Evolution 22:42-47.

Avise JC. 2000. Phylogeography: the History and Formation of Species. Cambridge, Massachusetts: Harvard University Press.

Bailey CD, Carr TG, Harris SA, and Hughes CE. 2003. Characterization of angiosperm nrDNA polymorphism, paralogy, and pseudogenes. Molecular Phylogenetics and Evolution 29:435-455. 
489

490

491

492

493

494

495

496

497

498

499

500

501

502

503

504

505

506

507

508

509

510

511

512

513

514

515

516

517

518

519

520

521

522

523

524

525

526

527

528

529

530

531

532

533

534

Byrne M. 2007. Phylogeography provides an evolutionary context for the conservation of a diverse and ancient flora. Australian Journal of Botany 55:316-325.

Clement M, Posada D, and Crandall K. 2000. TCS: a computer program to estimate gene genealogies. Molecular Ecology 9:1657-1660.

Cook BD, Pringle CM, and Hughes JM. 2008. Phylogeography of an island endemic, the Puerto Rican freshwater crab (Epilobocera sinuatifrons). Journal of Heredity 99:157-164.

Cowling RM, Proches S, and Partridge TC. 2009. Explaining the uniqueness of the Cape flora: incorporating geomorphic evolution as a factor for explaining its diversification. Molecular Phylogenetics and Evolution 51:64-74.

Cowling RM, Proches S, and Vlok JHJ. 2005. On the origin of southern African subtropical thicket vegetation. South African Journal of Botany 71:1-23.

Crandall KA, Bininda-Emonds ORP, Mace GM, and Wayne RK. 2000. Considering evolutionary processes in conservation biology. Trends in Ecology \& Evolution 15:290295.

Cummings MP, Neel MC, Shaw KL, and Otto S. 2008. A genealogical approach to quantifying lineage divergence. Evolution 62:2411-2422.

Drummond AJ, and Rambaut A. 2007. BEAST: Bayesian evolutionary analysis by sampling trees. BMC Evolutionary Biology 7:214.

Duker R, Cowling RM, du Preez DR, van der Vyver ML, Weatherall-Thomas CR, and Potts AJ. 2015a. Community-level assessment of freezing tolerance: frost dictates the biome boundary between Albany Subtropical Thicket and Nama-Karoo in South Africa. Journal of Biogeography 42:167-178.

Duker R, Cowling RM, Preez DRd, and Potts AJ. 2015b. Frost, Portulacaria afra Jacq., and the boundary between the Albany Subtropical Thicket and Nama-Karoo biomes. South African Journal of Botany 101:112-119.

Dynesius M, and Jansson R. 2000. Evolutionary consequences of changes in species' geographical distributions driven by Milankovitch climate oscillations. Proceedings of the National Academy of Sciences, USA 97:9115-9120.

Edwards SV, and Beerli P. 2000. Perspective: Gene divergence, population divergence, and the variance in coalescence time in phylogeographic studies. Evolution 54:1839-1854.

Fu Y-B, and Allaby R. 2010. Phylogenetic network of Linum species as revealed by non-coding chloroplast DNA sequences. Genetic Resources and Crop Evolution 57:667-677.

Funk WC, Blouin MS, Corn PS, Maxell BA, Pilliod DS, Amish S, and Allendorf FW. 2005. Population structure of Columbia spotted frogs (Rana luteiventris) is strongly affected by the landscape. Molecular Ecology 14:483-496.

Garrick RC, Sands CJ, Rowell DM, Hillis DM, and Sunnucks P. 2007. Catchments catch all: long-term population history of a giant springtail from the southeast Australian highlands - a multigene approach. Molecular Ecology 16:1865-1882.

Garrick RC, Sands CJ, Rowell DM, Tait NN, Greenslade P, and Sunnucks P. 2004. Phylogeography recapitulates topography: very fine-scale local endemism of a saproxylic 'giant' springtail at Tallaganda in the Great Dividing Range of south-east Australia. Molecular Ecology 13:3329-3344.

Gavin DG, Fitzpatrick MC, Gugger PF, Heath KD, Rodríguez-Sánchez F, Dobrowski SZ, Hampe A, Hu FS, Ashcroft MB, Bartlein PJ, Blois JL, Carstens BC, Davis EB, de Lafontaine G, Edwards ME, Fernandez M, Henne PD, Herring EM, Holden ZA, Kong W-s, Liu J, Magri D, Matzke NJ, McGlone MS, Saltré F, Stigall AL, Tsai Y-HE, and 
535

536

537

538

539

540

541

542

543

544

545

546

547

548

549

550

551

552

553

554

555

556

557

558

559

560

561

562

563

564

565

566

567

568

569

570

571

572

573

574

575

576

577

578

579

580

Williams JW. 2014. Climate refugia: joint inference from fossil records, species distribution models and phylogeography. New Phytologist 204:37-54.

Giordano AR, Ridenhour BJ, and Storfer A. 2007. The influence of altitude and topography on genetic structure in the long-toed salamander (Ambystoma macrodactulym). Molecular Ecology 16:1625-1637.

Graur D, and Martin W. 2004. Reading the entrails of chickens: molecular timescales of evolution and the illusion of precision. Trends in Genetics 20:80-86.

Hewitt GM. 2004. Genetic consequences of climatic oscillations in the Quaternary. Philosophical Transactions of the Royal Society of London Series B 359:183-195.

Ho SYW. 2007. Calibrating molecular estimates of substitution rates and divergence times in birds. Journal of Avian Biology 38:409-414.

Hoare DB, Mucina L, Rutherford MC, Vlok JHJ, Euston-Brown DIW, Palmer AR, Powrie LW, Lechmere-Oertel RG, Proches S, and Dold AP. 2006. Albany Thicket biome. In: Mucina $\mathrm{L}$, and Rutherford MC, eds. The vegetation of South Africa, Lesotho and Swaziland. Cape Town: South African National Biodiversity Institute.

Holmgren K, Lee-Thorp JA, Cooper GRJ, Lundblad K, Partridge TC, Scott L, Sithaldeen R, Talma AS, and Tyson PD. 2003. Persistent millennial-scale climatic variability over the past 25,000 years in Southern Africa. Quaternary Science Reviews 22:2311-2326.

Huson DH, and Bryant D. 2006. Application of phylogenetic networks in evolutionary studies. Molecular Biology and Evolution 23:254-267.

Jansson R, and Dynesius M. 2002. The fate of clades in a world of recurrent climatic change: Milankovitch oscillations and evolution. Annual Review of Ecology and Systematics 33:741-777.

Kay KM, Whittall JB, and Hodges SA. 2006. A survey of nuclear ribosomal internal transcribed spacer substitution rates across angiosperms: an approximate molecular clock with life history effects. BMC Evolutionary Biology 6:36.

Lischer HEL, Excoffier L, and Heckel G. 2013. Ignoring heterozygous sites biases phylogenomic estimates of divergence times: implications for the evolutionary history of Microtus voles. Molecular Biology and Evolution.

Mantel N. 1967. The detection of disease clustering and a generalized regression approach. Cancer Research 27:209-220.

Martínez-Meyer E, and Peterson AT. 2006. Conservatism of ecological niche characteristics in North American plant species over the Pleistocene-to-Recent transition. Journal of Biogeography 33:1779-1789.

Martínez-Meyer E, Peterson AT, and Hargrove WW. 2004. Ecological niches as stable distributional constraints on mammal species, with implications for Pleistocene extinctions and climate change projections for biodiversity. Global Ecology and Biogeography 13:305-314.

Moritz C. 1994. Defining 'evolutionarily significant units' for conservation. Trends in Evolution and Ecology 9:373-375.

Paradis E, Claude J, and Strimmer K. 2004. APE: analyses of phylogenetics and evolution in R language. Bioinformatics 20:289-290.

Partridge TC. 1997. Cainozoic environmental change in southern Africa, with special emphasis on the last 200000 years. Progress in Physical Geography 21:3-22.

Pennington TD, and Styles BT. 1975. A generic monograph of the Meliaceae. Blumea 22:419540. 
581 Peterson AT, Soberon J, and Sanchez-Cordero V. 1999. Conservatism of ecological niches in

582

583

584

585

586

587

588

589

590

591

592

593

594

595

596

597

598

599

600

601

602

603

604

605

606

607

608

609

610

611

612

613

614

615

616

617

618

619

620

621

622

623

624 evolutionary time. Science 285:1265-1267.

Ponniah M, and Hughes JM. 2006. The evolution of Queensland spiny mountain crayfish of the genus Euastacus. II. Investigating simultaneous vicariance with intraspecific genetic data. Marine and Freshwater Research 57:349-362.

Potts A, Hedderson T, Vlok JHJ, and Cowling RM. 2013a. Pleistocene range dynamics in the eastern Greater Cape Floristic Region: a case study of the Little Karoo endemic Berkheya cuneata (Asteraceae). South African Journal of Botany 88:401-413.

Potts AJ, Hedderson TA, and Cowling RM. 2013b. Testing large-scale conservation corridors designed for patterns and processes: comparative phylogeography of three tree species. Diversity and Distributions 19:1418-1428.

Potts AJ, Hedderson TA, Franklin J, and Cowling RMC. 2013c. The Last Glacial Maximum distribution of Albany Subtropical Thicket inferred from community distribution modelling. Journal of Biogeography 40:310-322.

Potts AJ, Hedderson TA, and Grimm GW. 2014. Constructing phylogenies in the presence of intra-individual site $p$ olymorphisms (2ISPs) with a focus on the nuclear ribosomal cistron. Systematic Biology 63:1-16.

Premoli AC, Mathiasen P, Cristina Acosta M, and Ramos VA. 2012. Phylogeographically concordant chloroplast DNA divergence in sympatric Nothofagus s.s. How deep can it be? New Phytologist 193:261-275.

Price BW, Barker NP, and Villet MH. 2007. Patterns and processes underlying evolutionary significant units in the Platypleura stridula L. species complex (Hemiptera : Cicadidae) in the Cape Floristic Region, South Africa. Molecular Ecology 16:2574-2588.

Price BW, Barker NP, and Villet MH. 2010. A watershed study on genetic diversity: phylogenetic analysis of the Platypleura plumosa (Hemiptera: Cicadidae) complex reveals catchment-specific lineages. Molecular Phylogenetics and Evolution 54:617-626.

R Core Team. 2015. R: A language and environment for statistical computing. Vienna, Austria: R Foundation for Statistical Computing

Richardson JE, Pennington RT, Pennington TD, and Hollingsworth PM. 2001. Rapid diversification of a species-rich genus of neotropical rain forest trees. Science 293:22422245.

Ritz CM, Zimmermann NFA, and Hellwig FH. 2003. Phylogeny of subsect. Meleuphorbia (A. Berger) Pax \& Hoffm. (Euphorbia L.) reflects the climatic regime in South Africa. Plant Systematics and Evolution 241:245-259.

Ronquist F, and Huelsenbeck JP. 2003. MrBayes 3: Bayesian phylogenetic inference under mixed models. Bioinformatics 19:1572-1574.

Rouget M, Cowling RM, Lombard AT, Knight AT, and Kerley GIH. 2006. Designing largescale conservation corridors for pattern and process. Conservation Biology 20:549-561.

Scharf TE, Codilean AT, de Wit M, Jansen JD, and Kubik PW. 2013. Strong rocks sustain ancient postorogenic topography in southern Africa. Geology.

Schliep KP. 2011. phangorn: phylogenetic analysis in R. Bioinformatics 27:592-593.

Soltis DE, Gitzendanner MA, Strenge DD, and Soltis PS. 1997. Chloroplast DNA intraspecific phylogeography of plants from the Pacific Northwest of North America. Plant Systematics and Evolution 206:353-373. 
625

626

627

628

629

630

631

632

633

634

635

636

637

638

639

640

641

642

643

644

645

646

647

648

649

650

651

652

653

654

655

656

657

658

659

660

661

662

663

664

665

666

667

Städler T, Haubold B, Merino C, Stephan W, and Pfaffelhuber P. 2009. The impact of sampling schemes on the site frequency spectrum in non-equilibrium subdivided populations. Genetics 182:205-216.

Stamatakis A. 2006. RAxML-VI-HPC: Maximum Likelihood-based phylogenetic analyses with thousands of taxa and mixed models. Bioinformatics 22:2688-2690.

Stamatakis A, Hoover P, and Rougemont J. 2008. A rapid bootstrap algorithm for the RAxML web servers. Systematic Biology 57:758-771.

Steenkamp Y, Van Wyk B, Victor J, Hoare D, Smith G, Dold T, and Cowling R. 2004. Maputaland-Pondoland-Albany. In: Mittermeier RA, Robles Gil P, Hoffman M, Pilgrim JD, Brooks TM, Mittermeier CG, Lamoreux J, and da Fonseca GAB, eds. Hotspots revisited: Earth's biologically richest and most endangered terrestrial ecoregions. Mexico City: CEMEX, 219-228.

Stephens M, Smith N, and Donnelly P. 2001. A new statistical method for haplotype reconstruction from population data. American Journal of Human Genetics 68:978-989.

Swart BL, Tolley KA, and Matthee CA. 2009. Climate change drives speciation in the southern rock agama (Agama atra) in the Cape Floristic Region, South Africa. Journal of Biogeography 36:78-87.

Swartz ER, Skelton PH, and Bloomer P. 2009. Phylogeny and biogeography of the genus Pseudobarbus (Cyprinidae): shedding light on the drainage history of rivers associated with the Cape Floristic Region. Molecular Phylogenetics and Evolution 51:75-84.

Swofford DL. 2002. PAUP*: Phylogenetic analysis using parsimony (*and other methods). Version 4.10b. Sunderland, Massachusetts: Sinauer Associates.

Taberlet P, Fumagalli L, Wust-Saucy AG, and Cosson JF. 1998. Comparative phylogeography and postglacial colonization routes in Europe. Molecular Ecology 7:453-464.

Talma AS, and Vogel JC. 1992. Late Quaternary paleotemperatures derived from a speleothem from Cango Caves, Cape Province, South Africa. Quaternary Research 37:203-213.

Tolley KA, Burger M, Turner AA, and Matthee CA. 2006. Biogeographic patterns and phylogeography of dwarf chameleons (Bradypodion) in an African biodiversity hotspot. Molecular Ecology 15:781-793.

Tzedakis P. 1993. Long-term tree populations in northwest Greece through multiple Quaternary climatic cycles. Nature 364:437-440.

VanDerWal J, Falconi L, Januchowski S, Shoo L, and Storlie C. 2011. SDMTools: Species distribution modelling tools: Tools for processing data associated with species distribution modelling exercises. $R$ package version 11-13 http://CRAN.Rproject.org/package $=$ SDMTools.

Vlok JHJ, Euston-Brown DIW, and Cowling RM. 2003. Acocks' Valley Bushveld 50 years on: new perspectives on the delimitation, characterisation and origin of subtropical thicket vegetation. South African Journal of Botany 69:27-51.

Wolfe KH, Li W-H, and Sharp PM. 1987. Rates of nucleotide substitution vary greatly among plant mitochondrial, chloroplast and nuclear DNAs. Proceedings of the National Academy of Sciences, USA 84:9054-9058.

Zachos J, Pagani M, Sloan L, Thomas E, and Billups K. 2001. Trends, rhythms, and aberrations in global climate 65 Ma to present. Science 292:686-693. 


\section{Data accessibility}

669 DNA sequences

670 Genbank rps16-trnQ intergenic spacer: KF180321-98

671 Genbank atpH-atpl intergenic spacer: KF180399-476

672 Genbank internal transcribe spacer 1, 5.8S ribosomal RNA gene, internal transcribed spacer 2:

673 KF443002-33, KY095713-57.

674 Genbank ncpGS gene: KY095758-827.

675

676

677 
679 Table 1 DNA summary statistics.

\begin{tabular}{|c|c|c|c|c|c|c|c|}
\hline Genome & Catchment & $\mathrm{n}$ & $h$ & $\mathrm{~S}$ & $\pi$ & $\mathrm{MT}_{\mathrm{R}}$ & $g s i_{\top}$ \\
\hline \multirow[t]{8}{*}{ cpDNA } & Overall & 78 & 20 & 28 & 0.0022 & $0.4510 * * *$ & \\
\hline & Groot $^{1}$ & 14 & 4 & 7 & 0.0015 & -0.0517 & $0.290(0.081) *$ \\
\hline & Olifants ${ }^{1}$ & 26 & 8 & 11 & 0.0016 & 0.0638 & $0.508(0.092) * *$ \\
\hline & Gamtoos & 18 & 5 & 11 & 0.0008 & -0.0250 & $0.991(0.067) * *$ \\
\hline & Sundays & 18 & 7 & 8 & 0.0013 & 0.1077 & $0.683(0.140) * *$ \\
\hline & Gro+Oli ${ }^{1}$ & 40 & 10 & 12 & 0.0017 & $0.0885 *$ & $0.947(0.155) * *$ \\
\hline & Oli+Gam & & & & & $0.3930 * * *$ & $0.353(0.097) * *$ \\
\hline & Sun+Gam & 38 & 11 & 16 & 0.0017 & $0.3460 * * *$ & $0.783(0.119) * *$ \\
\hline \multirow[t]{8}{*}{ ITS } & Overall & 75 & 68 & 54 & 0.0258 & $0.6234 * * *$ & \\
\hline & Groot $^{1}$ & 14 & 14 & 20 & 0.0128 & 0.1889 & $0.289(0.025) * *$ \\
\hline & Olifants $^{1}$ & 24 & 22 & 28 & 0.0133 & 0.1078 & $0.474(0.039) * *$ \\
\hline & Gamtoos & 15 & 13 & 23 & 0.0127 & $0.3433 *$ & $0.996(0.018) * *$ \\
\hline & Sundays & 22 & 21 & 21 & 0.008 & $0.1619 *$ & $0.994(0.034) * *$ \\
\hline & Gro+Oli ${ }^{1}$ & 38 & 34 & 29 & 0.0133 & $0.0829 *$ & $0.945(0.007) * *$ \\
\hline & Oli+Gam & & & & & $0.6448 * * *$ & $0.456(0.083)^{* *}$ \\
\hline & Sun+Gam & 37 & 34 & 35 & 0.0174 & $0.5622 * * *$ & $0.990(0.082) * *$ \\
\hline \multirow[t]{8}{*}{ ncpGS } & Overall & 69 & 13 & 11 & 0.0025 & $0.5717 * * *$ & \\
\hline & Groot $^{1}$ & 13 & 3 & 4 & 0.0006 & -0.1778 & $0.251(0.098) * *$ \\
\hline & Olifants ${ }^{1}$ & 22 & 5 & 3 & 0.001 & $-0.1435 *$ & $0.393(0.132) * *$ \\
\hline & Gamtoos & 14 & 5 & 5 & 0.0016 & 0.2020 & $0.187(0.060) * *$ \\
\hline & Sundays & 20 & 2 & 1 & 0.0001 & -0.1236 & $0.546(0.174) * *$ \\
\hline & Gro+Oli ${ }^{1}$ & 35 & 7 & 7 & 0.0009 & 0.0372 & $0.842(0.284) * *$ \\
\hline & Oli+Gam & & & & & $0.5454 * * *$ & $0.000(0.000) * *$ \\
\hline & Sun+Gam & 34 & 6 & 6 & 0.0008 & 0.0875 & $0.848(0.267) * *$ \\
\hline
\end{tabular}

$680 \mathrm{n}$ : number of samples; $h$ : number of haplotypes; $s$ : number of segregating sites; $\pi$ : nucleotide 681 diversity; $\mathrm{MT}_{\mathrm{R}}$ : Mantel tests $\mathrm{r}$ value (* $\left.\mathrm{p}<0.05 ;{ }^{* *} \mathrm{p}<0.01 ; * * * \mathrm{p}<0.001\right) ;$ gsi $i_{\mathrm{T}}$ : mean and standard 682 deviation (in brackets) of the ensemble genealogical sorting index, and values above a 683 threshold of 0.6 are in bold.

$684{ }^{1}$ The Groot and Olifants are sub-catchments within the primary Gouritz catchment that is referred to in the text. 


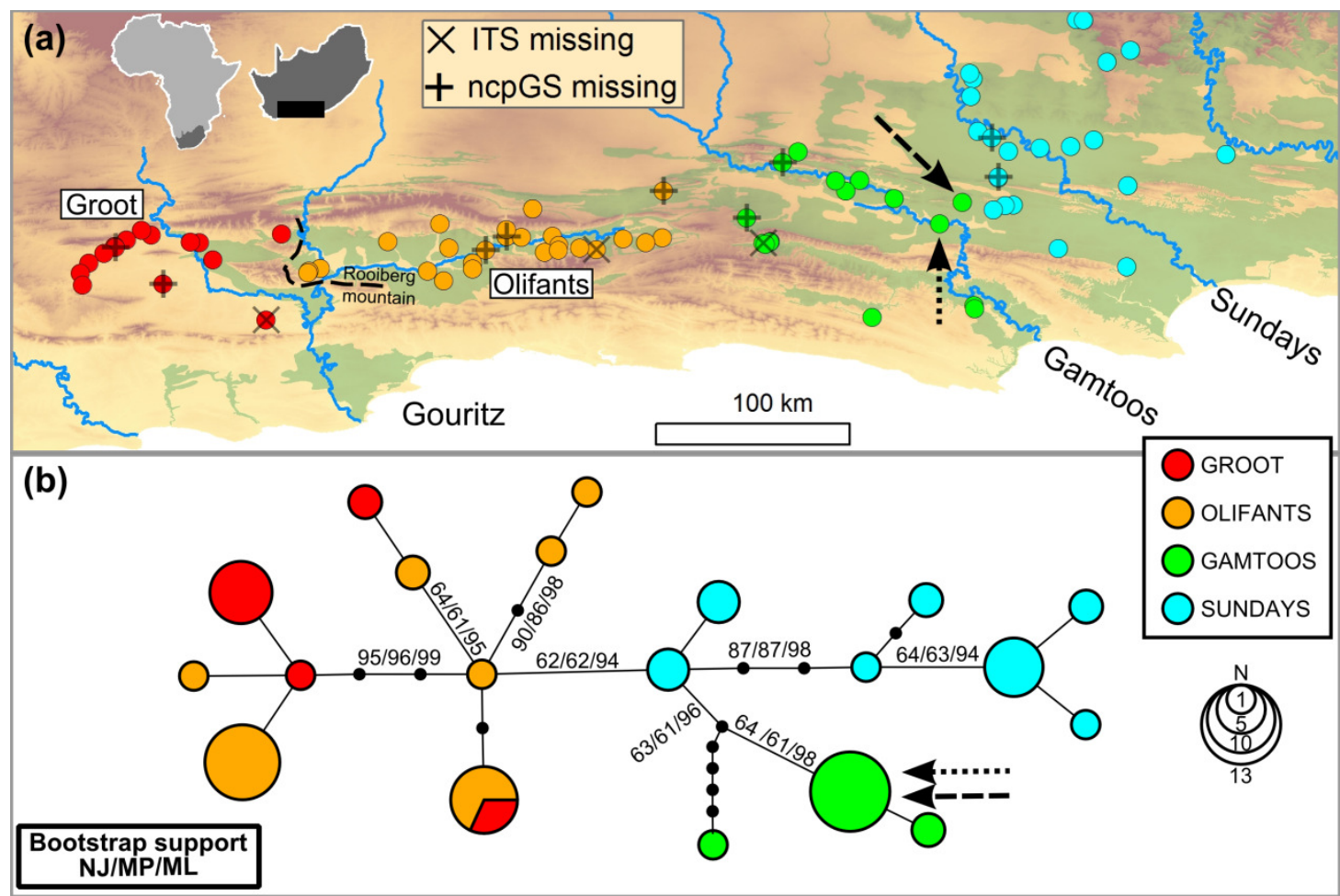

(c)
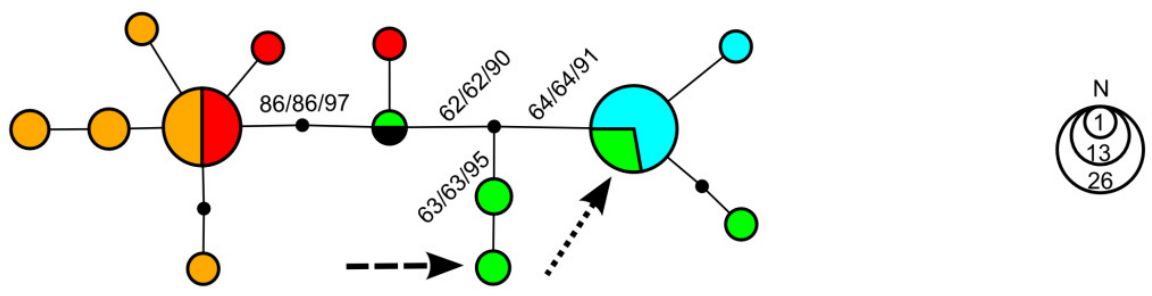

685

(d)

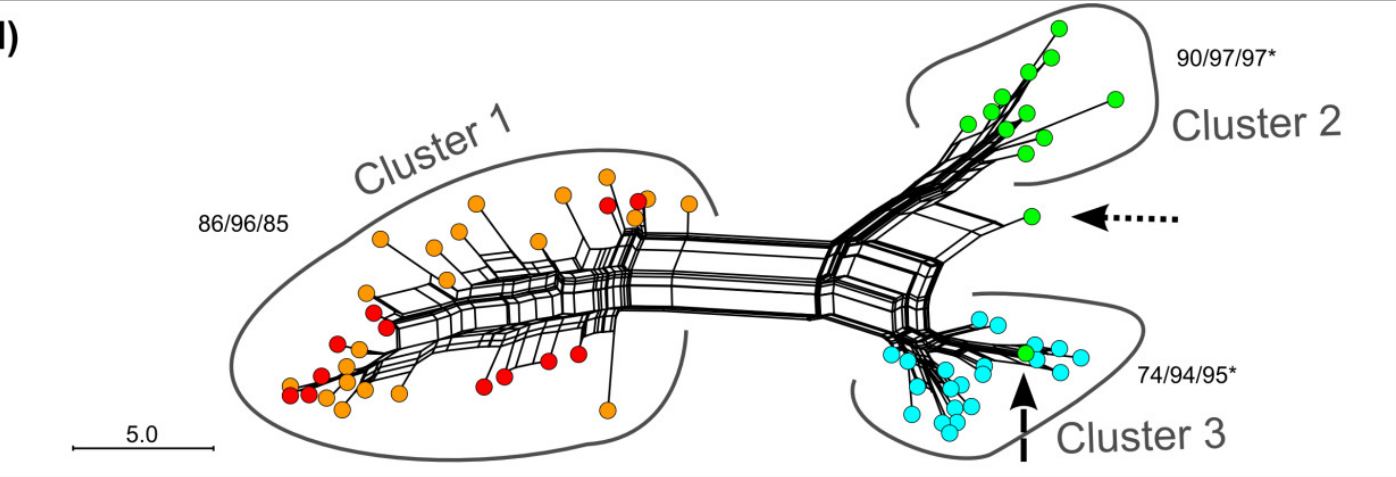

686 Figure 1 Distribution of Nymania capensis sampling localities within the Albany Subtropical

687 Thicket (light green) (a), and evolutionary relationships among accessions based on three

688 different molecular regions: cpDNA (b), low-copy nDNA (ncpGS) (c), and high-copy nDNA (ITS) 
689 (d). Arrows represent samples AJP0537 and AJP0810, respectively, which are discussed in the 690 text. Outgroup samples were pruned from these networks.

691 


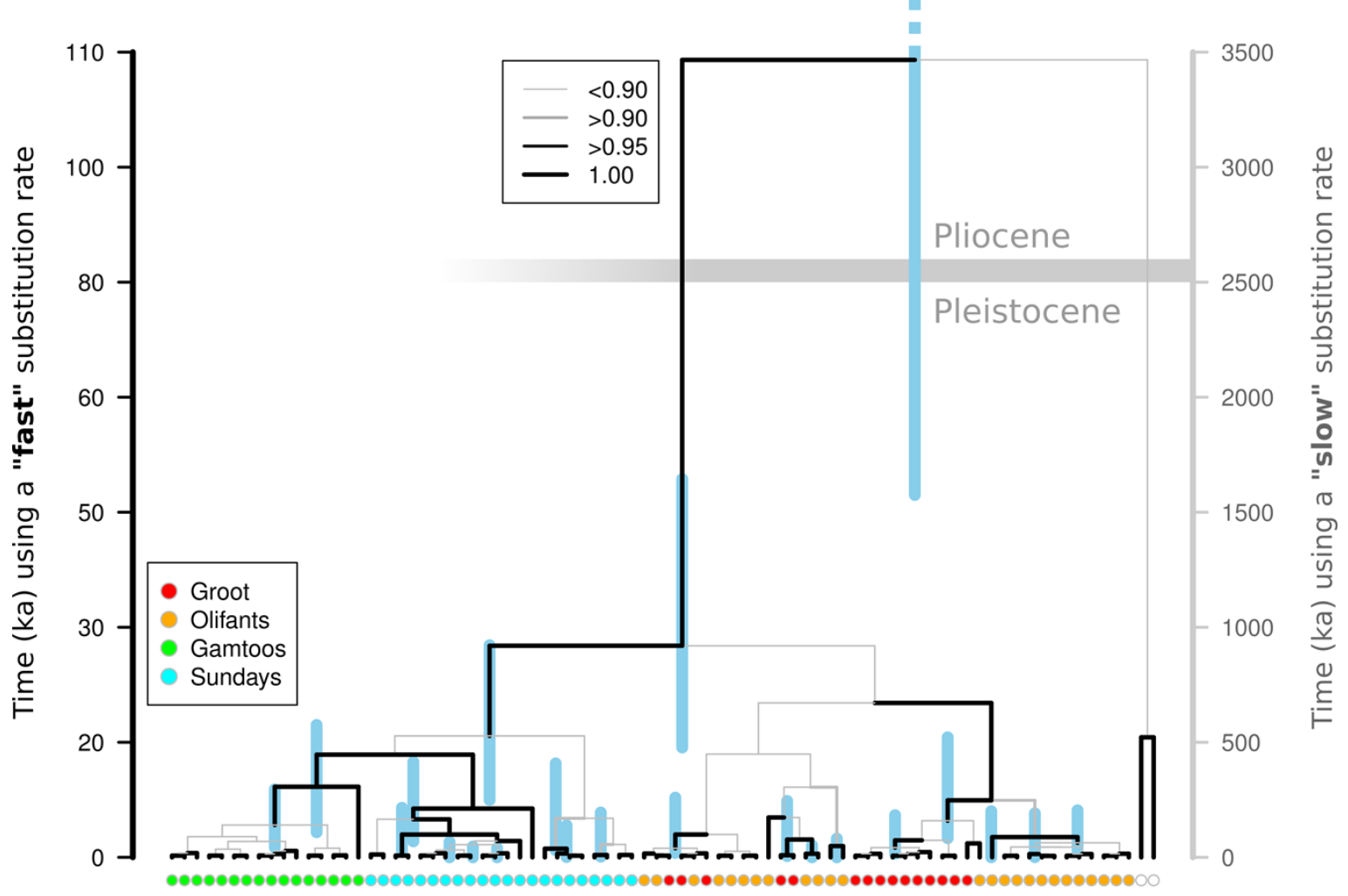

693

694 Figure 2 Molecular dating of Nymania capensis cpDNA sequences using majority rule Bayesian

695 chronogram generated in BEAST. The posterior probabilities of branches are shown using a

696 combination of branch width and colour. Nodes are centred on the median time to the most

697 common recent ancestor (TMRCA) with blue shaded bars indicating the distribution of the 95\%

698 HPD for each estimate. The timing of divergence estimates are show using a "slow" and "fast"

699 substitution rate (see text for details). The horizontal grey bar indicates the Pliocene-

700 Pleistocene boundary ( 2.6 Ma) under the "slow" substitution rate. 

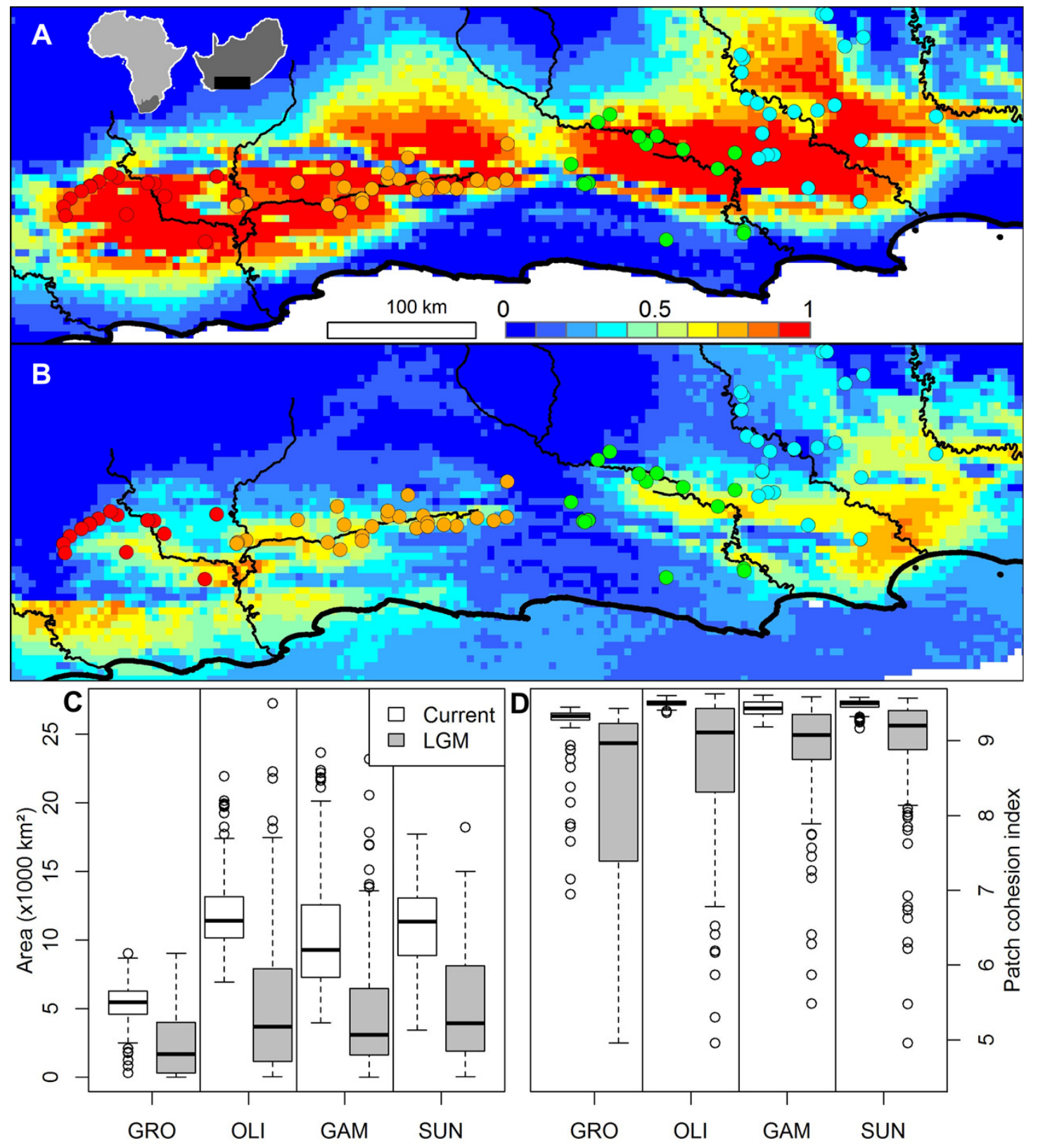

703

704 Figure 3 The ensemble of 216 species distribution models of Nymania capensis projected onto

705 (a) present and (b) Last Glacial Maximum (CCSM) climates, as well as the changes in climatically

706 suitable (c) area, and (d) patch cohesion index, within each basin. In the distribution maps, red

707 indicates greater certainty of presence, blue indicates greater certainty of absence, and green

$708(\sim 0.5)$ indicates areas of greatest model uncertainty. 